\title{
Printability of HDPE/Natural Fiber Composites with High Content of Cellulosic Industrial Waste
}

\author{
Luis Claudio Mendes", Sibele Piedade Cestari
}

Institute of Macromolecules Professor Eloisa Mano, Federal University of Rio de Janeiro, Centro de Tecnologia, Bloco J, Avenida Horácio Macedo, Rio de Janeiro, RJ, Brazil.

Email: *1cmendes@ima.ufrj.br

Received June $1^{\text {st }}, 2011$; revised June $17^{\text {th }}, 2011$; accepted June $22^{\text {nd }}, 2011$.

\begin{abstract}
In this paper, a continuous polymeric matrix highly filled with fiber of sugarcane bagasse has been obtained and its feasibility as an ink-absorbing material has been evaluated. In order to study the effect of the amount of cellulose fiber on the surface printability, contact angle measurement using different liquids-water-based inks, ethanol and ink for ink-jet printers-and printing tests were performed on composites of high density polyethylene (HDPE) and sugarcane bagasse (SCB). The composites were processed in a Haake internal mixer, using the SCB without any previous chemical treatment or compatibilizer. The differential scanning calorimetry (DSC) and derivative thermogravimetry (TG/ $D T G)$ revealed an increase in the thermal stability and in the degree of crystallinity of the HDPE. The optical microscopy (OM) and scanning electron microscopy (SEM) showed that the cellulosic material was homogeneously embedded within the HDPE matrix. In order to assess the resistance of the composite sample to the pull strength of the printer, tensile tests were applied to the composites and the results were compared to known paper samples. The best result was achieved in the composite with the highest content of SCB, as well as the shortest drying time.
\end{abstract}

Keywords: Recycling, Composite, Printing Properties, HDPE, Sugarcane Bagasse

\section{Introduction}

Nowadays one of the major concerns of society is to preserve natural resources, because the awareness of its finitude. The search for sustainable solutions is visible in all sectors of economy [1]. Even raw materials from renewable font must have its levels of use reduced, since they make use of finite natural resources (fertilizers, water).

The use of polymeric materials has reduced the consumption of finite natural resources in many industrial applications [2]. The cellulose industry plays an important role in these sustainability matters, and is a sector of the productive chain that can be benefited by the use of polymeric materials. The use of thermoplastics in some commodities can reduce the necessary volume of cellulose in its composition, and even replace some established products - as paper, for instance, which already has a synthetic substitute for some printing applications.

Composite materials like plastic lumber [3], woodplastic composites [4] and natural fiber reinforced composites [5] were developed intending to achieve more sustainable solutions for the construction and reinforced plastics market. The proposition is, through the application of recycled plastics as raw material (raising its lifecycle and reducing its disposal in the environment), and using renewable-source reinforcing fillers, elaborate ecofriendly materials with wide application (as substitutes for some wood and automotive products). Cui et al. [6] studied the properties of wood fiber-reinforced recycled plastic composites manufactured from sawdust and postconsumer HDPE. It was observed that the incorporation of wood fibers results in higher melting and slower crystallization rate of the composites. Also its thermal and mechanical properties varied significantly according to plastic content, length of wood fiber and compatibilizer content of the composites.

Most of the existing plastic lumbers use recycled plastics only. Martins et al. [7], when studying mechanical properties of IMAWOOD ${ }^{\circledR}$ plastic lumber, inform its composition: LDPE/HDPE 3:1 blend, obtained from postconsumed plastic bags recovered from municipal dump. But they are designed to work mainly as structural parts, and its success as a commoditie is attached to the effi- 
ciency of the plastic waste selective collection.

The wood-plastic composites (WPC) have actually substituted some wood products (the medium density fiberboard-MDF- has overcome the traditional plywood boards in the Brazilian furniture market), but many compatibilizers and fiber treatments must be used in order to achieve the strong mechanical properties they need $[8$, 9]. And natural fiber reinforced composites (NFRC) intend to substitute inorganic for natural fiber reinforcing fillers [10], aiming to improve the properties of the neat polymer [11]. Singh et al. [12] developed jute fiber reinforced phenolic composite profiles as an alternative to wooden frames in buildings, intending to develop composites for structural applications. Most studies in the polyolefin/natural fibers composites area chemically treats the cellulosic fibers, to improve its adhesion and/or to bleach the fibers. Gwon et al. [13] studied the modifycation of wood fibers using alkali treatment and coupling agent reactions, mixed with polypropylene resin, concluding that the fiber treatments increased physical properties due to the introduction of compatible molecular structure onto the wood fiber surfaces.

None of these cited composites - plastic lumber, WPC and NFRC - have been elaborated just to gather the cellulosic filler with polymer, neither dealing with poor adhesion between polymer and filler, nor aiming to improve mechanical properties. But the development of such material would be an interesting application to cellulosic filler in a polymeric composite, and could lead to a sustainable material for the printing industry, and reduce the consumption of cellulosic pulp in several know applications.

Therefore, the idea of this work is to create a sustainable material making use of the polarity of cellulose as vehicle for receiving and retaining ink, in order to obtain a continuous polymeric matrix highly filled with fiber of sugarcane bagasse and to evaluate its feasibility as an ink-absorbing material. The goal of the experiment was to achieve simple blends, with few components.

As this work focus on the environmental aspects of the experiment, it was decided not to bleach the SCB fibers, to preserve its natural polarity and to avoid the generation of pollutant effluents (chlorine and hydrogen peroxide based). At first, the idea was to use recycled HDPE, but the difficulties in dealing with a heterogeneous material, associated with raw filler, lead to the use of virgin HDPE instead of the recycled polymer.

\section{Experimental}

\subsection{Materials}

The materials were high density polyethylene (HDPE) named Petrochem HC 7260 — density equal $0.958 \mathrm{~g} \cdot \mathrm{cm}^{-3}$; melt flow rate (MFR) equal $8 \mathrm{~g} \cdot 10 \mathrm{~min}^{-1}$ - supplied by Ipiranga Petroquímica, and sugarcane bagasse $(\mathrm{SCB})$ waste from HC Sucroquímica sugarcane plant (Campos dos Goytacazes, RJ, Brasil).

The latter was used without any previous chemical treatment, and then grinded and sifted using a sieve with 40 mesh, according to the ISO 3301. The SCB fiber that passed through the sieve was used in the composite. Before the composite preparation, both materials were dried in an oven, at $105^{\circ} \mathrm{C}$, for 2 hours.

\subsection{Composite and Specimen Preparation}

Composites of HDPE/SCB were prepared varying the SCB content from 0 to $70 \mathrm{wt} \%$ - named $100 / 0,80 / 20$, $50 / 50$ and $30 / 70$ - in a Haake internal mixer, at $180^{\circ} \mathrm{C}$, $60 \mathrm{rpm}$, for 10 minutes. After that, the material was compression molded as a plate of $1 \mathrm{~mm}$ thickness, in a hydraulic press at $200^{\circ} \mathrm{C}, 10,000 \mathrm{psi}$, for 5 minutes, being subsequently cooled in another hydraulic press, at $25^{\circ} \mathrm{C}$, 430 psi, for 5 minutes.

\subsection{Optical Microscopy and SEM Analysis}

The morphology of the materials was noticed by usual techniques. Optical microscopy (OM) observation was performed with an Olympus stereo microscope, model SZH10, equipped with a Nikkon Coolpix 5400 digital camera attached.

Triturated SCB, processed HDPE and the three composites were analyzed. Scanning electron microscopy (SEM) was performed using a Fei Company microscope model Quanta 200, using specimens coated with $300 \mathrm{~nm}$ gold particles $(\mathrm{Au})$ applied by JEOL equipment model JFC 1500. Cryogenically fractured transversal sections and surfaces of the samples were assessed.

\subsection{Differential Scanning Calorimeter (DSC)}

The differential scanning calorimetry (DSC) was done using a TA equipment model TA Q1000. Three thermal cycles were performed. In first one, the sample was heated from $0^{\circ} \mathrm{C}$ to $200^{\circ} \mathrm{C}$, at heating rate of $10^{\circ} \mathrm{C} \cdot \mathrm{min}^{-1}$, under nitrogen atmosphere. In order to eliminate the thermal history, it was left at $200^{\circ} \mathrm{C}$ for 2 minutes. The second one was a cooling cycle from $200^{\circ} \mathrm{C}$ up to $0^{\circ} \mathrm{C}$, at $10^{\circ} \mathrm{C} \cdot \mathrm{min}^{-1}$. At the third cycle, the same temperature range and heating rate of the first cycle were applied.

The crystalline melting temperature $\left(T_{m}\right)$ and the degree of crystallinity $\left(X_{c}\right)$ of the HDPE were obtained considering the second heating cycle curves. The $X_{c}$ was determined based on the ratio between the $\Delta \mathrm{H}$ of the HDPE in the composite and the $\Delta \mathrm{H}$ of the $100 \%$ crystalline HDPE (290 J/g), adjusted according to the percentage of the polyolefin in the composite. 


\subsection{Thermogravimetry}

Thermogravimetry/derivative thermogravimetry (TG/DTG) was performed in a TA model Q500 equipment, from $30^{\circ} \mathrm{C}$ to $700^{\circ} \mathrm{C}$, at heating ratio of $10^{\circ} \mathrm{C} \cdot \mathrm{min}^{-1}$, in a nitrogen atmosphere. The weight loss, initial and final degradation temperatures $-\mathrm{T}_{\text {onset }}, \mathrm{T}_{\text {final }}$ respectively - were evaluated.

\subsection{Contact Angle}

The measurement of contact angle was performed in a Ramé-Hart N.R.L goniometer, model 100 - 00, using RHI 2001 Imaging Software. It measures the angle between a plane tangent to a drop of liquid over a solid surface, and the plane of this surface. Four liquids were used: distilled water $(\mathrm{DW})$, ethanol $(\mathrm{EOH})$, mixture $\mathrm{DW} / \mathrm{EOH}$ and inkjet ink (IJI).

\subsection{Printing Test}

Printing tests were done using a Cannon printer, model MP 160. Samples of $110 \times 110 \times 0.5 \mathrm{~mm}$ of each composite were attached to a sheet of A4 paper. Text, color and black-and-white drawings were printed onto the composites surface, and pictures were taken after the drying time. The photographs were taken with a Canon EOS XT 350D digital camera, 35 - 80 mm lens.

\subsection{Tensile-Strain Test}

The tensile test was performed in an Instron tester model 5569 , according to the ASTM D 882, using a load cell of $10 \mathrm{kN}$, test speed of $25 \mathrm{~mm} / \mathrm{min}$., and rectangular specimen of $10 \times 100 \mathrm{~mm}$. The test was also carried out over known paper samples (board and kraft), to compare the results. The Young modulus, the stress and elongation at yield, the stress and elongation at break were evaluated. The results consider the mean of 5 specimens of each sample.

\section{Results and Discussion}

The distribution of fiber length revealed that $77 \%$ of the ground SCB has passed through the 20 mesh sieve. In this fraction, the higher portion-36\% - passed through the 100 mesh sieve. Since smaller fibers present a better dispersion into the polymeric matrix, it was decided to use all the material that passed through the 40 mesh sieve (around $1 \mathrm{~mm}$ to lower fiber lengths), corresponding to $66 \%$ of the triturated SCB. The ratios between fines/ HDPE percentages in the composites were calculated, in order to evaluate the influence of the fines in the properties of the composites -0.14 for the $80-20,0.55$ for the 50 - 50 and 1.28 for the $30-70$ composite.

\subsection{Optical Microscopy and SEM Analysis}

The OM and SEM photomicrographies of the composites (Figures 1-2) revealed fine dispersion between polymer and filler. Comparing the particle size of the triturated filler to those of the composites shows that some shearing occurred during the processing in the Haake mixer.

The good interaction between the two materials may have come from the variety of sizes of the ground SCB particles, which included a lot of fines. Also the presence of lignin may have worked as a compatibilizing agent in the composites, as seen in some studies $[4,14]$. The SEM revealed that the SCB particles were completely encapsulated by the HDPE, even in the 30 - 70 composite. It also confirms fine dispersion between the materials.

\subsection{Differential Scanning Calorimetry}

The DSC curves are shown in Figure 3, and the results of the composites and its parent materials are in Table 1. The SCB curve presented an intense peak at the first heating cycle-between $50^{\circ} \mathrm{C}-170^{\circ} \mathrm{C}$ (maximum value was around $120^{\circ} \mathrm{C}$ ), ascribed to the loss of moisturewhich disappeared in the second heating cycle. For the composites, considering the second heating cycle, no variation was observed in the $T_{m}$ of the HDPE $\left(132^{\circ} \mathrm{C}\right)$, denoting that the average size of the crystals did not change. At all the heating cycles, there was a raise in the $X_{c}$ depending on the content of SCB in the composites.

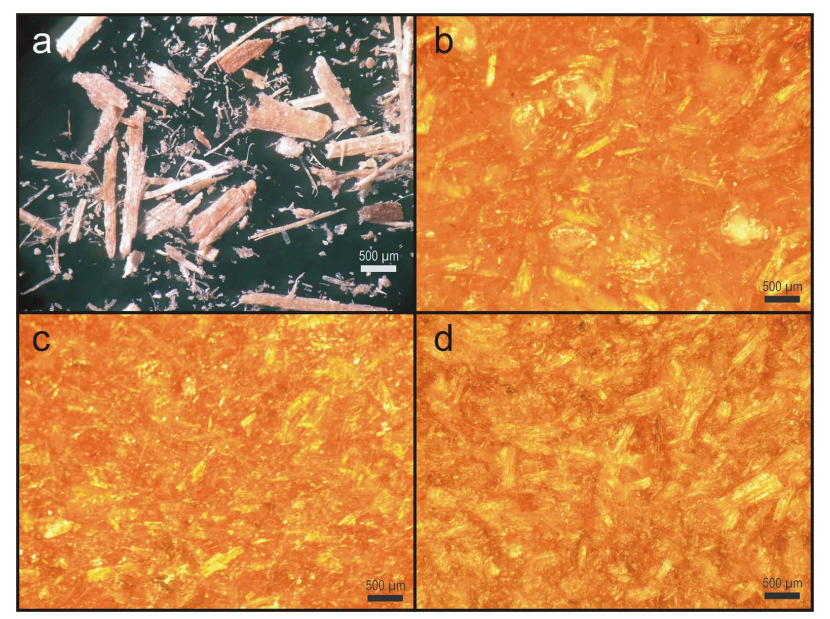

Figure 1. OM photomicrographies of the materials: (a) ground SCB, (b) 80 - 20 composite, (c) 50 - 50 composite and (d) 30 - 70 composite.

Table 1. Melting temperature and degree of crystallinity of the composites.

\begin{tabular}{cccc}
\hline HDPE/SCB composite & $\boldsymbol{T}_{\boldsymbol{m}}\left({ }^{\circ} \mathbf{C}\right)$ & $\boldsymbol{T}_{\boldsymbol{c}}\left({ }^{\circ} \mathbf{C}\right)$ & $\boldsymbol{X}_{\boldsymbol{c}}(\mathbf{\%})$ \\
\hline $\mathbf{1 0 0}-\mathbf{0}$ & 132 & 120 & 66 \\
$\mathbf{8 0}-\mathbf{2 0}$ & 132 & 119 & 84 \\
$\mathbf{5 0}-\mathbf{5 0}$ & 132 & 121 & 68 \\
$\mathbf{3 0 ~ - ~ 7 0}$ & 132 & 120 & 83 \\
\hline
\end{tabular}



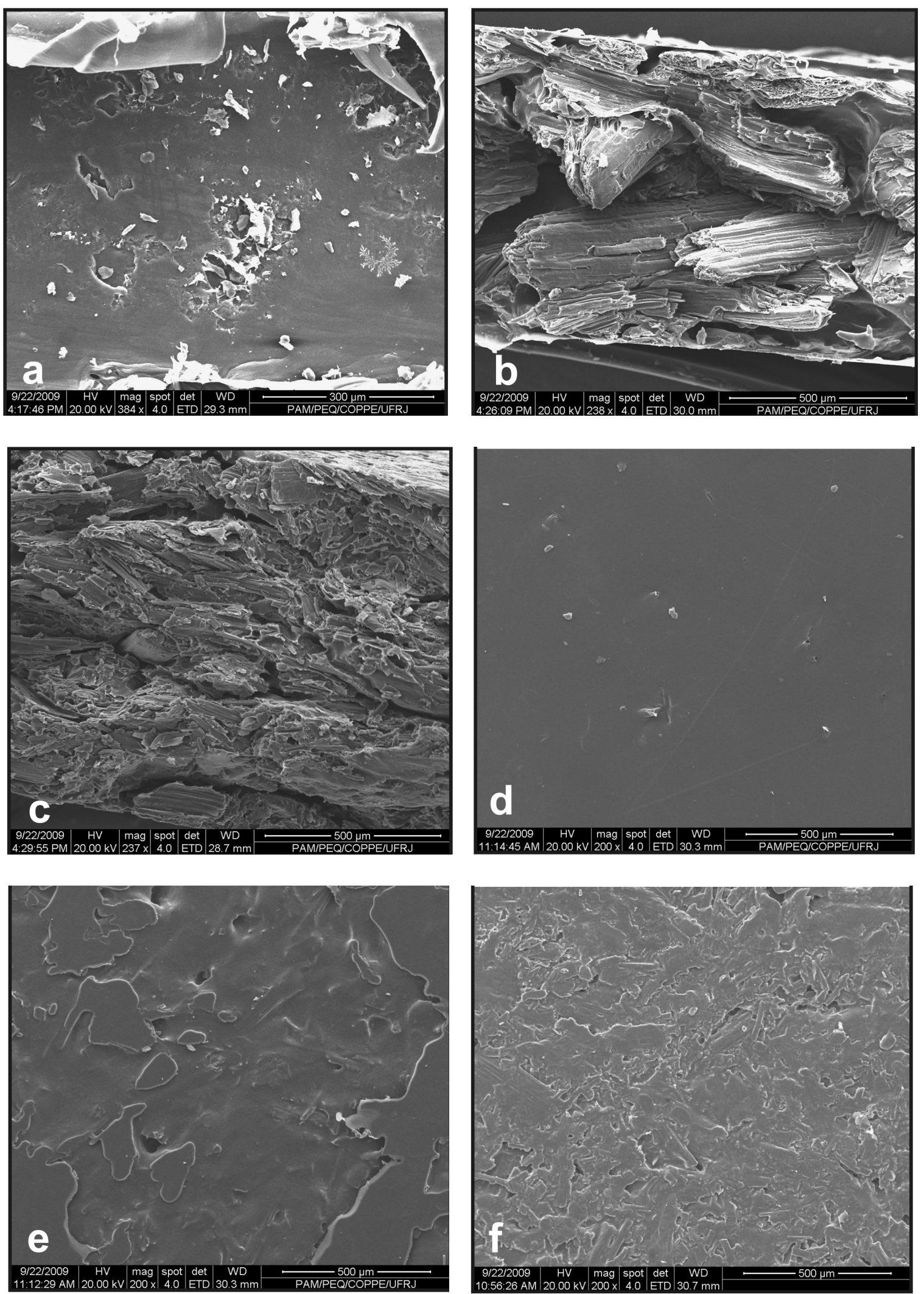

Figure 2. SEM photomicrographies of the materials: 80 - 20 composite (a) section and (d) surface, 50 - 50 composite (b) section and (e) surface, and 30 - 70 composite (c) section and (f) surface. 


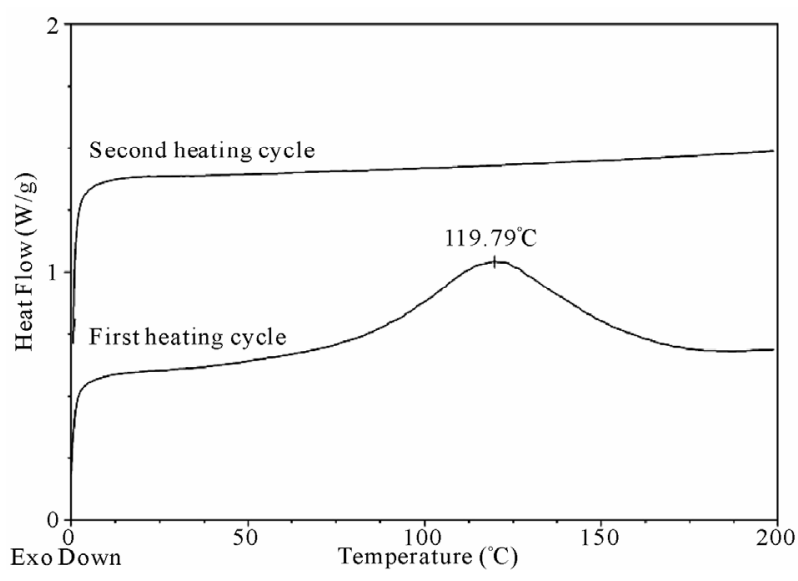

(a)

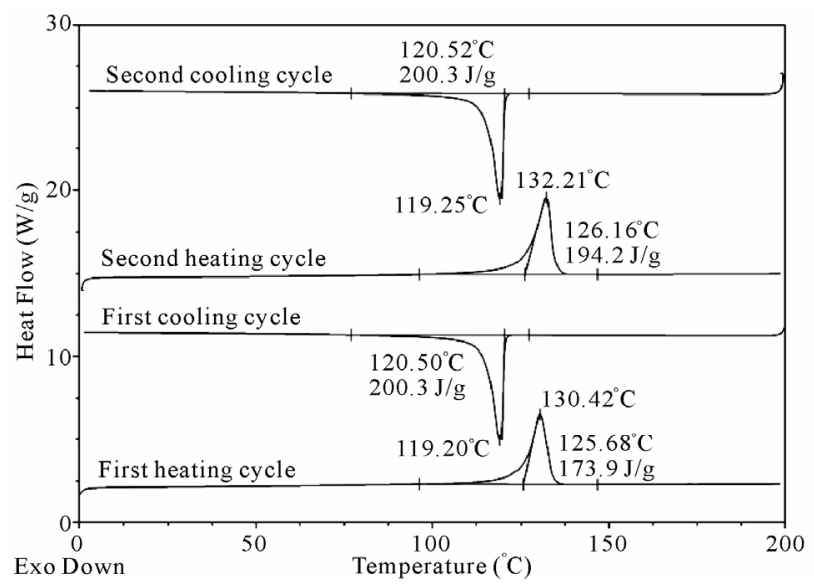

(c)

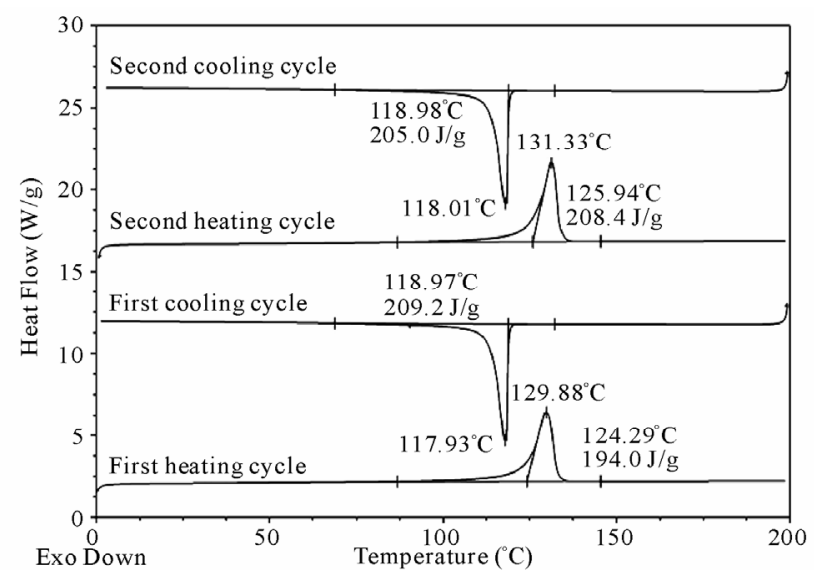

(b)

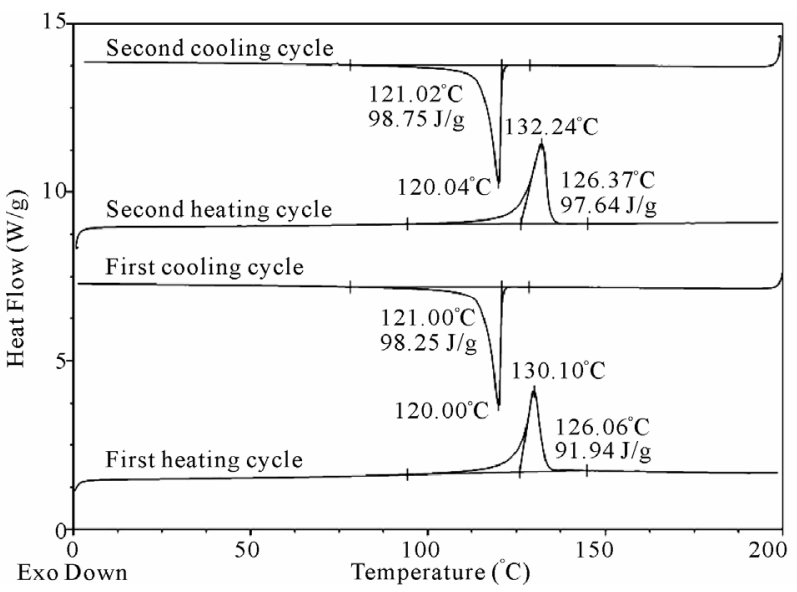

(d)

Figure 3. DSC curves of the materials: (a) SCB, (b) 80 - 20 composite, (c) 50 - 50 composite and (d) 30 - 70 composite.

This increase in the $X_{c}$, associated with no variation in the $T_{c}$, may be due to some transcrystallization. Commonly, after melting, the bulk molten of a semicrystalline polymer can recrystallize under cooling. It takes place under homogeneous nucleation, and where the amount of the crystalline portion has the same order of magnitude as the initial material. Concerning to the composites, transcrystallization is a special case of crystallization where a heterogeneous nucleation is feasible along a fiber surface. The transcrystallization is a function of nucleating activity of the fiber surface and crystallization kinetics of the resin matrix [15]. Also, this phenomenon was described by $\mathrm{Na}$ et al. [16], when performing morphological investigations of an isotactic polypropylene matrix induced by synthetic fibres.

\subsection{Thermogravimetry}

Table 2 lists the initial and final degradation temperatures $\left(\mathrm{T}_{\text {onset }}\right.$ and $\mathrm{T}_{\text {final }}$, respectively), the maximum degradation temperature $\left(T_{\max }\right)$ and the amount of remaining residue of the parent materials and the composites. The HDPE curve (Figure 4(a)), as expected, showed a single step degradation, and the entire sample burned, leaving no residue. The SCB and 30/70 composite curves are shown in Figures 4(b) and 4(e). The SCB presented three different steps of weight loss. The first one is probably due to loss of moisture. At the second stage, the ascending part of the derivative thermogravimetry (DTG) curve presented a shoulder and a peak-highlighted in a

Table 2. $T_{\text {onset }} T_{\text {final }}$ and $T_{\text {max }}$ of the materials.

\begin{tabular}{ccccc}
\hline $\begin{array}{c}\text { HDPE/SCB } \\
\text { Composite }\end{array}$ & $\begin{array}{c}\mathbf{T}_{\text {onset }} \\
\left({ }^{\circ} \mathbf{C}\right)\end{array}$ & $\begin{array}{c}\mathbf{T}_{\text {final }} \\
\left({ }^{\circ} \mathbf{C}\right)\end{array}$ & $\begin{array}{c}\mathbf{T}_{\text {máx }} \\
\left({ }^{\circ} \mathbf{C}\right)\end{array}$ & $\begin{array}{c}\text { Residue } \\
(\mathbf{\%})\end{array}$ \\
\hline $\mathbf{1 0 0 / 0}$ & 433 & 500 & 461 & - \\
$\mathbf{8 0} / \mathbf{2 0}$ & $307 / 459$ & 500 & $354 / 478$ & - \\
$\mathbf{5 0 / 5 0}$ & $303 / 444$ & 550 & $349 / 472$ & 3 \\
$\mathbf{3 0 / 7 0}$ & $258 / 448$ & 550 & $295 / 351 / 472$ & 10 \\
$\mathbf{S C B}$ & 292 & 575 & $344 / 496$ & 2 \\
\hline
\end{tabular}




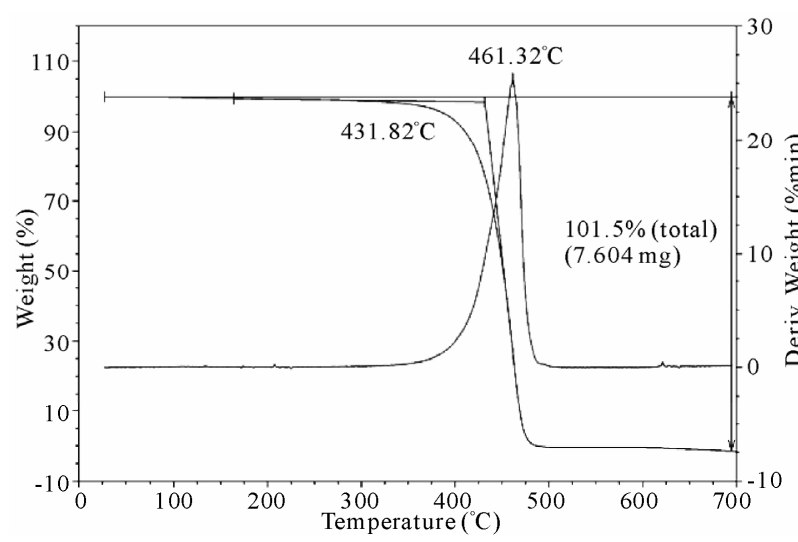

(a)

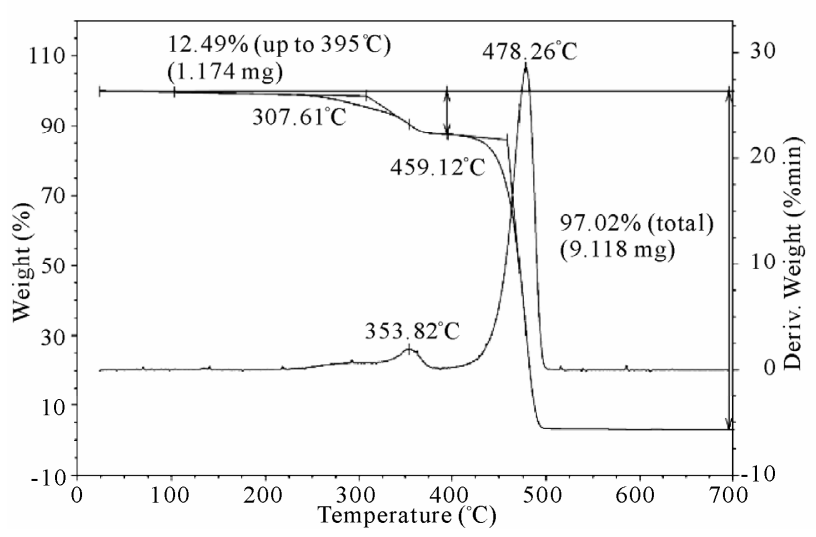

(c)

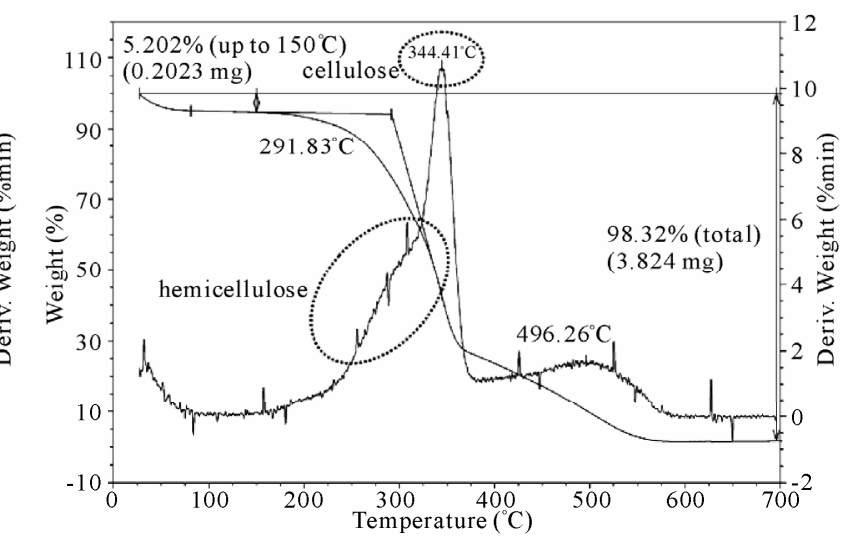

(b)

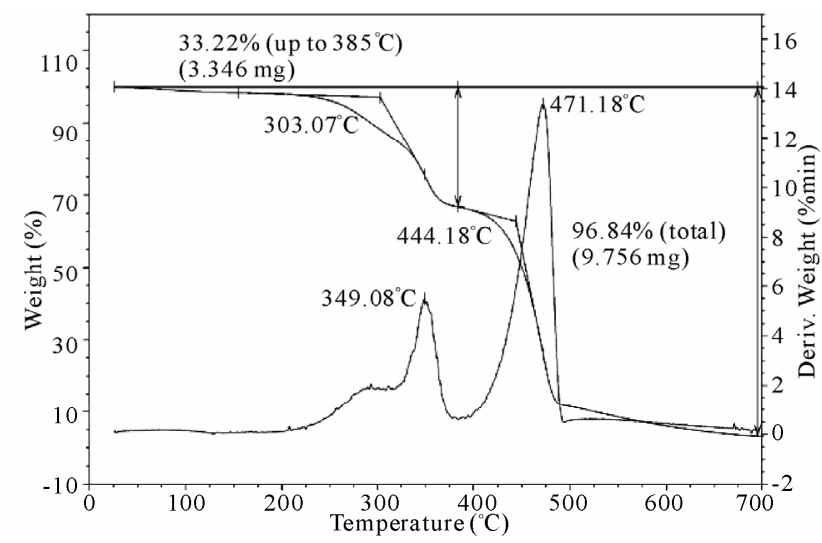

(d)

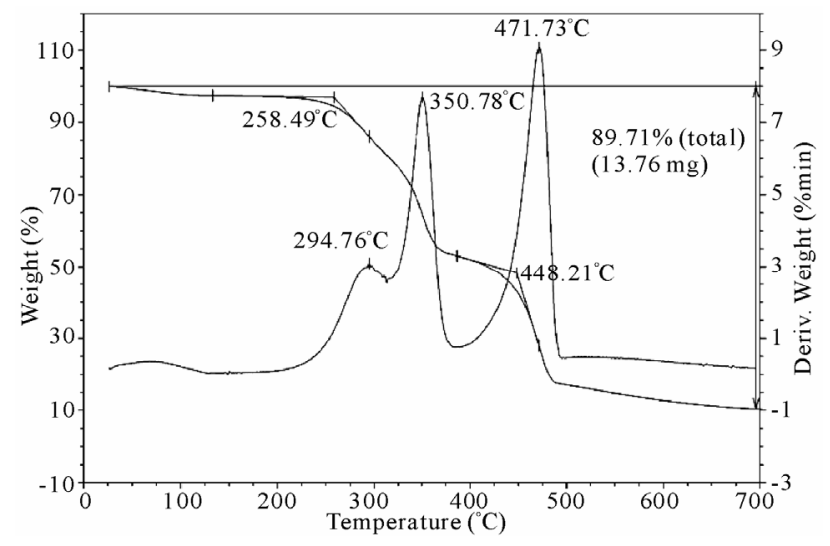

(e)

Figure 4. TG/DTG degradation curves of the materials: (a) HDPR, (b) SCB, (c) 80 - 20 composite and (d) 50 - 50 composite; (e) 30 - 70 composite.

dot circle-ascribed to the burn of hemicellulose and cellulose, respectively. And the third step was attributed to the degradation of lignin.

The weight loss curves of the composites showed burn steps similar to the parent materials. There was mutual influence in the thermal parameters considered in this study. The $\mathrm{T}_{\text {onset }}, \mathrm{T}_{\text {final }}$ and $\mathrm{T}_{\max }$ temperatures of the HDPE were shifted to higher values, indicating a raise in its thermal stability due to the presence of the SCB.

Concerning to the $30-70$ composite, there was a change in the burn profile of the SCB. What first seem to be a shoulder and a peak on the SCB thermogram, turned 
into two well-defined peaks $\left(\mathrm{T}_{\max }=295\right.$ and $\left.351^{\circ} \mathrm{C}\right)$. The amount of residue increased as the content of SCB in the composite raised.

\subsection{Contact Angle}

Contact angle test results for the four liquids (DW, EOH, $\mathrm{DW} / \mathrm{EOH}$ and IJI) are shown in Table 3. Figure 5 graphically shows an overall comparison. The composites presented high repellency to DW (water). The 100 - 0 composite presented nearly no variation to the three other liquids. The addition of $20 \%, 50 \%$ and $70 \%$ of SCB influenced the results for $\mathrm{EOH}, \mathrm{DW} / \mathrm{EOH}$ and IJI contact angles.

Concerning to $\mathrm{DW} / \mathrm{EOH}$ and IJI contact angle values, the composites showed a similar behavior. For EOH, there is a linear decrease of the contact angle depending on the $\mathrm{SCB}$ content. The results clearly show that the increase of the SCB content in the composites raises the absorption efficiency of the tested liquids.

\subsection{Printing Test}

The composite sheets were cleaned with ethyl alcohol before being printed, having no other surface treatment. The printing tests (Figure 6, Online Resource 1) showed the composites' capability of absorbing inkjet ink. It took from 6 to 24 hours for the ink to completely dry on the other composites, and the 80 - 20 composite was unable to retain it at all.

Observing the $80-20$ and 50 - 50 printing tests, one can see the ink had formed drops that did not spread on the sheet surface, resulting in a blurred, non-graphic quality, which was easily smudged. On the $30-70$ composite the ink was completely dried and partially absorbed within a reasonable time (about 1 hour). The quality of the printing improved as the cellulose content in the composite raised.

\subsection{Tensile-Strain Test}

The tensile test provided by the Young modulus, tensile stress at maximum load, tensile strain at maximum load, stress at break and strain at break, and the results are shown in Table 4. The Young modulus decreases with lower amounts of SCB filler, but for the 50 - 50 and 30 70 composites it reaches a value close to neat HDPE. The increase of the amount of filler decreases the tensile stress, tensile strain, break strength and break elongation values, as seen by Mulinari et al. [17] when studying sugarcane bagasse/HDPE composites obtained by extrusion. The moduli of the plastic materials are inferior to those of commercial paper, but the elongation of the 80 20 composite is similar.

\section{Conclusions}

These results show that the association of triturated SCB with a polymeric matrix brings up fine results in terms of printability, thermal and mechanical properties. In general, the developed materials seem to fit the purpose of aggregating cellulosic industrial waste using a polyole-

Table 3. Contact angles for the materials.

\begin{tabular}{ccccc}
\hline \multirow{2}{*}{ Composite HDPE/SCB } & \multicolumn{3}{c}{ Liquids } \\
\cline { 2 - 5 } & DI water & Ethanol & DI water/ethanol mix 50 - 50\% & Inkjet ink \\
\hline $\mathbf{1 0 0}-\mathbf{0}$ & $75 \pm 13$ & $23 \pm 7$ & $23 \pm 7$ & $20 \pm 4$ \\
$\mathbf{8 0}-\mathbf{2 0}$ & $61 \pm 12$ & $20 \pm 2$ & $37 \pm 4$ & $25 \pm 5$ \\
$\mathbf{5 0}-\mathbf{5 0}$ & $71 \pm 11$ & $12 \pm 4$ & $46 \pm 4$ & $31 \pm 6$ \\
$\mathbf{3 0}-\mathbf{7 0}$ & $77 \pm 12$ & $8 \pm 3$ & $42 \pm 8$ & $26 \pm 7$ \\
\hline
\end{tabular}

Table 4. Tensile parameters.

\begin{tabular}{|c|c|c|c|c|c|}
\hline Material & $\begin{array}{l}\text { Young modulus } \\
\text { (MPa) }\end{array}$ & $\begin{array}{l}\text { Stress at Maximum Load } \\
\text { (MPa) }\end{array}$ & $\begin{array}{c}\text { Elongation at Maximum Load } \\
(\%)\end{array}$ & $\begin{array}{l}\text { Stress at break } \\
\text { (MPa) }\end{array}$ & $\begin{array}{c}\text { Elongation at break } \\
(\%)\end{array}$ \\
\hline HDPE & $590 \pm 54$ & $24.1 \pm 1.6$ & $14.1 \pm 1.7$ & $19.3 \pm 1.3$ & $24.2 \pm 8.0$ \\
\hline $80 \%-20 \%$ & $356 \pm 19$ & $7.7 \pm 0.8$ & $3.1 \pm 0.4$ & $6.1 \pm 0.6$ & $3.6 \pm 0.5$ \\
\hline $50 \%-50 \%$ & $512 \pm 128$ & $4.4 \pm 1.7$ & $1.2 \pm 0.3$ & $3.5 \pm 1.4$ & $1.4 \pm 0.3$ \\
\hline Board paper & $1568 \pm 87$ & $22.6 \pm 1.1$ & $2.6 \pm 0.2$ & $22.4 \pm 1.0$ & $2.6 \pm 0.2$ \\
\hline Kraft paper & $2218 \pm 195$ & $67.1 \pm 4.3$ & $4.5 \pm 0.2$ & $66.4 \pm 4.2$ & $4.5 \pm 0.2$ \\
\hline
\end{tabular}




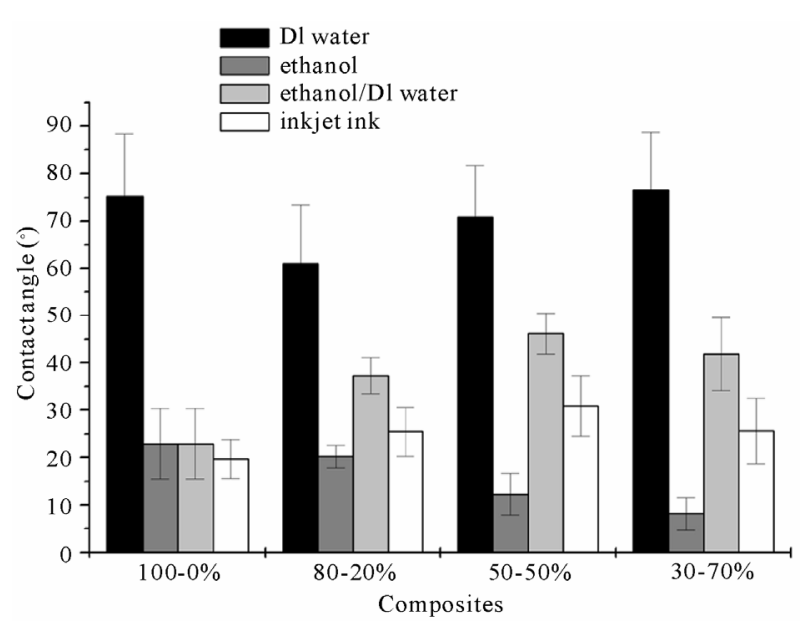

Figure 5. Comparative graphic contact angle $\mathrm{x}$ solids.

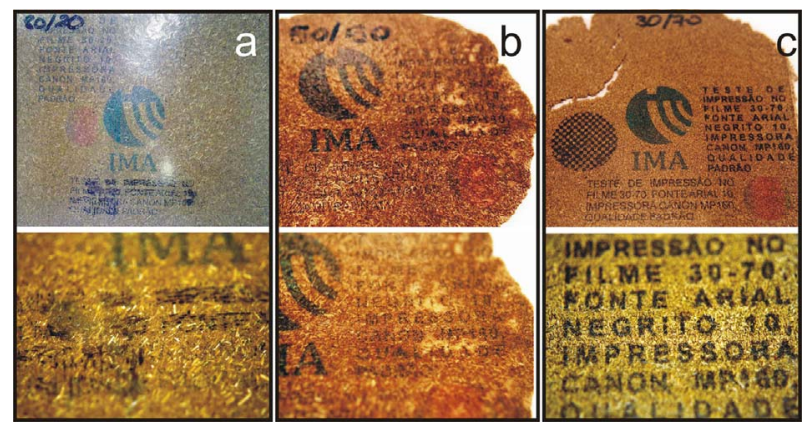

Figure 6. Printing test of the composites: (a) 80 - 20 composite, (b) 50 - 50 composite and (c) 30 - 70 composite.

finic matrix, in order to create a printing surface through a simple, low cost and eco-friendly composite.

\section{Acknowledgements}

The authors thank to the Conselho Nacional de Desenvolvimento Científico e Tecnológico $(\mathrm{CNPq})$ and to the Fundação Coordenação do Aperfeiçoamento de Pessoal de Nível Superior (CAPES), and to the Nosso Futuro Comum blog community headed by the economist Hugo Penteado, for supporting this investigation.

\section{REFERENCES}

[1] L. Yu, K. Dean and L. Li, "Polymer Blends and Composites from Renewable Resources," Progress in Polymer Science, Vol. 31, No. 6, 2006, pp. 576-602. doi:10.1016/j.progpolymsci.2006.03.002

[2] Z. Liu, S. Z. Erhan, D. E. Akin and F. E. Barton, “'Green' Composites from Renewable Resources: Preparation of Epoxidized Soybean Oil and Flax Fiber Composites," Journal of Agricultural and Food Chemistry, Vol. 54, No. 6, 2006, pp. 2134-2137. doi:10.1021/jf0526745

[3] M. Breslin, "Demand for Plastic Lumber Remains High," In: K. I. Redighieri and D. A. Costa, Eds., Mechanical
Properties and Water Uptake of Composites of Recycled LDPE and Wood Particles, Revista Universidade Rural, Serie Ciencias Exatas e da Terra, No. 25, 2006, pp. 28-35.

[4] G. A. Wiedman, "Fibra de coco e resinas de origem vegetal para produção de componentes de mobiliário e da construção civil," Ph.D. Dissertation, Universidade de São Paulo, São Paulo, 2002.

[5] Y. H. Cui, J. Tao, B. Noruziaan, M. Cheung and S. Lee, "DSC Analysis and Mechanical Properties of Wood-Plastic Composites," Journal of Reinforced Plastics and Composites, Vol. 29, 2010, pp. 278-289. $\underline{\text { doi: } 10.1177 / 0731684408097766}$

[6] A. F. Martins, J. C. M. Suarez and E. B. Mano, "Produtos poliolefíNicos Reciclados Com Desempenho Superior Aos Materiais Virgens Correspondentes," Polímeros: Ciência e Tecnologia, Vol. 9, No. 4, 1999, pp. 27-32.

[7] S. M. Luz, J. Del Tio, G. J. M. Rocha, A. R. Gonçalves and A. P. Del'Arco Jr., "Cellulose and Cellulignin from Sugarcane Bagasse Reinforced Polypropylene Composites: Effect of Acetylation on Mechanical and Thermal Properties," Composites Part A, Vol. 39, No. 9, 2008, pp. 1362-1369. doi:10.1016/j.compositesa.2008.04.014

[8] G. Saini, A. K. Narula, V. Choudhary and R. Bhardwaj, "Effect of Particle Size and Alkali Treatment of Sugarcane Bagasse on Thermal, Mechanical, and Morphological Properties of PVC-Bagasse Composites," Journal of Reinforced Plastics and Composites, Vo. 29, 2010, pp. 731-740.

[9] S. M. Luz, A. C. Pires and P. M. C. Ferrão, "Environmental Benefits of Substituting Talc by Sugarcane Bagasse Fibres as Reinforcement in Polypropylene Composites: Ecodesign and LCA as Strategy for Automotive Components," Resources, Conservation and Recycling, Vol. 54, No. 12, 2010, pp. 1135-1144.

[10] S. M. Luz, A. R. Gonçalves and A. P. Del'Arco Jr., "Mechanical Behavior and Microstructural Analysis of Sugarcane Bagasse Fibres Reinforced Polypropylene Composites," Composites Part A, Vol. 38, No. 6, 2007, pp. 1455-1461.

[11] B. Singh and M. Gupta, "Performance of Pultruded Jute Fibre Reinforced Phenolic Composites as Building Materials for Door Frame," Journal of Polymers and the Environment, Vol. 13, No. 2, 2005, pp. 127-137. doi:10.1007/s10924-005-2944-X

[12] J. G. Gwon, S. Y. Lee, S. J. Chun, G. H. Doh and J. H. Kim, "Effect of Chemical Treatments of Wood Fibers on the Physical Strength of Polypropylene Based Composites," Korean Journal of Chemical Engineering, Vol. 27, No. 2, 2010, pp. 651-657.

[13] B. A. Acha, N. E. Marcovich and M. M. Reboredo, "Lignin in Jute Fabric - Polypropylene Composites," Journal of Applied Polymer Science, Vol. 113, No. 3, 2009, pp. 1480-1487.

[14] A. A. Apostolov, M. Evstatiev, Z. Denchev, K. Friedrich and S. Fakirov, "Effect of Composition on Transcrystallization of Polypropylene in Drawn PET/PP Blend," Journal of Materials Science, Vol. 42, No. 4, 2007, pp. 
1245-1250. doi:10.1007/s10853-006-1395-7

[15] B. Na, M. Guo, J. Yang, H. Tan, Q. Zhang and Q. Fu, "Crystal Morphology and Transcrystallization Mechanism of Isotactic Polypropylene Induced by Fibres: Interface Nucleation versus Bulk Nucleation," Polymer International, Vol. 55, No. 4, 2006, pp. 441-448.

doi:10.1002/pi.1996
[16] D. R. Mulinari, H. J. C. Voorwald, M. O. H. Cioffi, M. L. C. P. da Silva, T. G. da Cruz and C. Saron, "Sugarcane Bagasse Cellulose/HDPE Composites Obtained by Extrusion," Composites Science and Technology, Vol. 69, No. 2, 2009, pp. 214-219.

doi:10.1016/j.compscitech.2008.10.006 